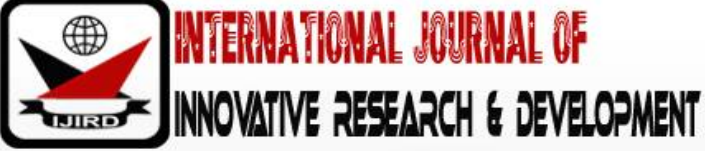

ISSN 2278 - 0211 (Online)

\section{Entrepreneurship Development in Plateau Central Senatorial Zone of Plateau State, Nigeria (2011-2017)}

Goyin Longul Philemon
Doctoral Student, Department of Public Administration and Local Government,
University of Nigeria, Nsukka, Nigeria
Micah Godiya
Civil Servant, Plateau State Universal Basic Education Board, Nigeria
Obeta, M. Uchejeso
Doctoral Student, Department of Public Administration and Local Government,
University of Nigeria Nsukka, Nigeria

\begin{abstract}
:
There have been calls in recent times from government at all levels, international organizations, non-governmental organizations and private individuals alike regarding Entrepreneurship Development in every nook and crannies of Nigeria, stemming from the inability of the government to successfully cater for the basic needs and welfare of its citizenry, hence the very essence of the need to develop entrepreneurship amongst the people so as to augment and supplement governments effort to make ends meet and support the government. This article therefore assesses Entrepreneurship Development in Plateau Central Senatorial Zone of Plateau State. The study covers the periods between 2011-2017, it adopted solely the use of secondary sources to gather the needed data for this research. The paper extensively reviewed literatures in the areas under study where qualitative content analysis was employed to analyze the data gathered. The study revealed that there is presence of entrepreneurial activities in the zone which are thriving. Some constraints impeding on the success of entrepreneurship in the Zone were also highlighted to include Infrastructural deficiencies, Inadequate working capital, Lack of entrepreneurial education amongst others. The paper proffered useful working recommendations gearing towards revamping and improving entrepreneurship development in the zone and the country at large.
\end{abstract}

Keywords: Entrepreneurship, development, senatorial, zone, plateau state

\section{Introduction}

\subsection{Background to the Study}

Among countries of the world, especially in the developing countries, there is growing acceptance as to the need to address the poor conditions of the citizens. Most citizens of these countries are greatly ravaged by endemic poverty to the extent that feeding has become a major challenge among numerous others. Thus, improving the material wellbeing of the people is not only a source of concern for individual countries in the world, but has also assumed an international agenda to which great attention is being placed on. The growing acceptance of the need to reverse the undesirable conditions can also be noticed in Nigeria in the numerous poverty alleviation programs aimed at addressing the challenges posed by poverty among her citizens. It is observed that an average Nigerian still lives a life that subsists below the absolute poverty line (Ezenagu, 2014). To this end, a lot of economic reform programs or strategies have evolved with much emphasis being placed on self-reliance via entrepreneurship and its numerous small and medium enterprises. As Ezenagu (2014) will further express, the economic success of most emergent countries of the world are traceable to the contributions made by self-reliant individuals (entrepreneurs), through their numerous small and medium enterprises. Development therefore is believed to depend on entrepreneurs who make a living by creating new businesses and new ideas. In supporting this submission, Osunde (2016) quoted the report of the Small and Medium Enterprises Development of Nigeria (SMEDAN), the public agency responsible for the promotion of entrepreneurship in Nigeria. In that report, the agency stated as thus:

Micro, Small and Medium Enterprises (MSMEs) represents one of the important sectors of the Nigerian economy. It currently represents $96 \%$ of the businesses in Nigeria and contributes $75 \%$ of the national employment. Of the 17.2 million MSMEs in Nigeria over 17 million are micro enterprises. Thus, the growth in this sector is directly correlated with the growth in the economy and in the increase of employment in Nigeria. 
Entrepreneur therefore refersto an individual who start or organize commercial enterprises, especially one involving financial risk (Oxford Advanced Learner's Dictionary, Tenth Edition). To an economist, entrepreneur is one who brings resources, labour, materials and other assets into combination that make their value greater than before and who introduce changes through innovations and new order (Ezenagu, 2014). Therefore, entrepreneurs are the risk takers who create businesses by assembling all the factors of production in their efforts to start and operate businesses and make profits reasonable enough to live befitting life. In fact, they are the main stay of the economy.

Hence, entrepreneurship in a developing country like Nigeria is believed to exist when people in the society, especially rural farmers/manufacturers, produced more products/goods than they needed, as such; they had to exchange the surpluses with those who needed them within their immediate and neighboring communities (Ezenagu, 2014). This exchange of goods for goods or services was based on trade by barter initially, until commodity money was developed and used. This exchange system encouraged specialization among producers, and the communities came to realize that they can concentrate on the areas of production where they are best fitted.

Consequent on the above, the culture of entrepreneurship in Nigeria as captured by Nicks(2008); Raimi and Towobola, (2011) in the words of Ani (1995) cited in Ezenagu (2014) is an adventure of an independent man who can be said to have strong will to succeed and might engage the services of others, like friends, mates, in-laws etc., to help him/her in his/her work of production. Through this way, Nigerians, right from time immemorial, engaged in entrepreneurship. Early engagement in entrepreneurial activities are characterized with production or manufacturing in which case the producer often started with small capital, most of it from his own savings.

Modern entrepreneurship in Nigeria started with the coming of the colonial masters who brought in their wears and made Nigerians their middle men (Ezenagu, 2014). In this way, modern entrepreneurship was conceived. Most of the modern entrepreneurs were engaged in retail trade or sole proprietorship. Ezenagu (2014) expressed further by giving reasons why entrepreneurship had not developed as it ought to have over many years of its practice in Nigeria. Accordingly, one of the major factors which had, in many ways, discouraged the flow of entrepreneurial development in local communities in Nigeria is the value system brought about by formal education. For many decades people had the opportunity of being employed in the civil service, because those days the economy was large enough to absorb people into the prestigious occupation. Again, the contact between the Nigerian entrepreneurs and foreign entrepreneurs during the colonial era was very detrimental and the competitive business strategy of the foreign entrepreneurs was ruinous and also against moral standard established in the society. For instance, the United African Company (UAC) that was responsible for a substantial percentage of the import and export trade of Nigeria had the policy of dealing directly with producers and refused to make use of Nigerians. The refusal of the expatriates to utilize the services of local businessmen inhibited their expansion and acquisition of necessary skills and attitude. Because of this, many eventually folded up. Those that folded built up resentment against business, which became very demoralizing to other prospective entrepreneurs (Ezenagu, 2014). As a result, the flow of entrepreneurship in the country was slow.

But with more people being educated and the fact that government could no longer employ most school leavers, various economic programs to encourage individuals to go into private business and be self-reliant were initiated (Theodore, and Gieger 2011 in Ezenagu, 2014). Such economic policy and programs that are geared towards self-reliance for individuals are programs such as Anchor Program introduce in 2015 by the Central Bank of Nigeria. This program has been said to play a catalytic role in making Nigerians to key in to Small and Medium Scale agriculture. The resultant impact of this is the rice revolution in the states of Kebbi, Nassarawa, Ebonyi and Anambra. Another initiative is the Young Initiative Development program (YEDP). This program was also introduced by Central Bank of Nigeria on 15th March, 2016. Its main objective was to encourage youths to embrace entrepreneurship. This program provided youths the avenue to acquire skills and upon completion, they are financially empowered with the sum of between 3-10 million naira to embark on self-employment enterprise. Others are, open apprenticeship scheme, graduate employment program etc., and other policies that encourage or make it easy for entrepreneurs to acquire the needed funds, e.g, Peoples Bank of Nigeria, Funds for Small-Scale Industries (FUSSI), Co-operative Societies etc., were established to assist entrepreneurs.

In Nigeria, policies are constantly being made with concerted efforts to implement them to ensure the growth of entrepreneurship in the country in order to ensure that it contribute maximally to economic development. But they are confronted by many challenges which are perennial in nature hampering the sustainability and otherwise of entrepreneurship. It is on this note that this work is set to evaluate entrepreneurial development in Plateau Central Senatorial Zone of Plateau state: issues and challenges.

\subsection{Statement of the Problem}

When discussing topics relating to entrepreneurship development in Nigeria, especially in the Central Zone of Plateau State in particular), certain issues as well as challenges tend to arise in the minds of people. These issues revolving around planning and managerial competence, infrastructural facilities, management of credit facilities, financial practice and a host of others comes to the fore. Over the years, governments in Nigeria have continued to, through intervention programs like the Small and Medium Enterprises Development Agency of Nigeria (SMEDAN), Central Bank of Nigeria, etc. find ways to create grounds capable of positioning the economy in such manners that allow entrepreneurial activities to excel.

It is noteworthy bringing to the fore that through the above efforts of government and its agencies, some evident entrepreneurs have succeeded and continue to succeed in their various areas of specialty. While others have succeeded, in most remote communities of Plateau Central Zone, quite a number of these enterprises find it difficult to stand the test of time; most of them collapse within short time of their establishment. In such situation of mixed entrepreneurial progress, it will be difficult to record any break in the vicious circle of poverty among the people, especially in the rural 
communities. Therefore, finding solutions to issues and challenges responsible for such situation of mixed entrepreneurial progression in our rural communities is indeed a viable research venture.

Having established the problem for the paper, it is necessary at this point to raise pertinent questions which are considered to be at the core of the subject matter:

- Are there entrepreneurial activities in Plateau Central Senatorial Zone of Plateau State?

- What are the impacts of entrepreneurship development in Plateau Central Senatorial Zone of Plateau State?

- What are the major constraints inhibiting entrepreneurial development in Plateau Central Senatorial Zone of Plateau State?

- How can the identified challenges be mitigated to provide conducive operational environment for entrepreneurs in Plateau Central Senatorial Zone of Plateau State?

\subsection{Objectives of the Study}

Based on the above indicated questions, the broad objective of this paper is to examine the impact of entrepreneurship development in Plateau Central Senatorial Zone of Plateau State. The specific objectives of the study are to:

- Ascertain the presence of presence of entrepreneurial activities in Plateau Central Senatorial Zone of Plateau State.

- Determine the impact of entrepreneurship development in Plateau Central Senatorial Zone of Plateau State.

- Identify the constraints encountered by entrepreneurs in Plateau Central Senatorial Zone of Plateau State.

- Proffer ways that the identified challenges can be mitigated to provide conducive operational environment for entrepreneurs in Plateau Central Senatorial Zone of Plateau State.

\subsection{Significance of the Study}

Theoretically, this paper will be of great significance as seeks to contribute to the existing body of knowledge in fields 'public and Business management.

Empirically, the significance is evident from the fact that it is unique in its own way by focusing on entrepreneurial development in a less economically recognized zone unlike other researches which focus on entrepreneurship activities in economically viable societies in the North-Central zone. In fact, the researchers are yet to specifically find any work that focuses on the areas of analysis as highlighted in the objective above. At the end of the work, researchers having interest in the same area shall stand to benefit from this work. Thus, prospective and practicing entrepreneurs, cooperative societies, especially those in the Plateau Central Senatorial Zone of Plateau State, and other practicing managers of business and the government will find this work worth the while. The paper will also serve as a background and catalyst to future researchers and scholars who may wish to venture into the areas of promoting entrepreneurship development in Plateau Central Senatorial Zone of Plateau State.

Likewise, the conclusion which this research may expose, could lead to improvement and efficiency in Plateau State with regards to entrepreneurship.

\subsection{Scope of the Study}

The paper is a study of entrepreneurial development in Plateau Central Senatorial Zone of Plateau State, highlighting the issues and challenges faced by entrepreneurs in the Zone. The period covers from 2011 to 2017.

\section{Conceptual Clarifications}

\subsection{Concept of Entrepreneurship}

There is no unanimity amongst scholars regarding the concept of entrepreneurship as its meaning is often dependent on the scholar's background and area of academic specialty.

According to Timothy, and John (2016) cited in Kpelai, (2009:39) argues that an entrepreneur is someone who identifies economic opportunities, gather the necessary resources, creates a new or improves on an existing business ventures to satisfy some needs in an economy.

According to Onmonya (2014:1), while economists view entrepreneurship as the taking of risks in expectation of profit by combining factors of production within a way that something new with greater value is produced; the management scientists conceive of it to mean a creative, innovative and strategic process of starting and revitalizing an organization and continuous improvement of its goods and services. To an accountant, Onmonya posits that entrepreneurship is concerned with activities of individuals with realistic investment ideas and is able to take advantage of investment ideas and opportunities that will yield return on investment.

Also hinging on the lack of unanimity on the concept of entrepreneurship, Ajekwe and Ibiamke (2016) explain that there exist several schools of thought which view the notion of entrepreneurship from different perspectives. These perspectives as they explain include:

- Entrepreneurship as starting up your own business and becoming self-employed

- Being an entrepreneur in an existing organization

- Being innovative in exploiting personal and organizational opportunities by adopting a particular approach to work, study or life in general; and 
- Being enterprising: becoming more independent and self-reliant throughout life, by gaining the necessary knowledge, skills and attitudes, a mindset of independence, a dislike for paid jobs and overdependence on family and government.

Based on the foregoing, Onmonya maintained that entrepreneurship is used to describe the creative, innovative, risk taking and organizational process and functions of individuals who initiate, run and nurture business ventures. He explained that the ultimate aim of entrepreneurs is to enjoy the reward of resultant profit, independence, personal achievement and fame. He however warned that there are risks which an entrepreneur must be ready to take, and identified such risks to include business or financial losses as well as social, psychological and health related risks.

Also, Kpelai (2013), defined entrepreneurship as a process of owning and managing a new venture or improving on an existing product or services that creates value, assuming the accompanied risks and receiving the resulting rewards and independence. He explained further that entrepreneurship is a process that results into new products, new methods, new markets or forms of organization while helping to create wealth by creating demand in the market from a newly introduced innovation.

Generally, notwithstanding the outlay of the concept of entrepreneurship, Ajekwe and Ibiamke (2016) state that there are four forms of entrepreneurship and they are known as Independent, Public, Corporate and Social entrepreneurship. The Independent entrepreneurship as they explain is the one which a person or group of persons establish for profit, while the Public entrepreneurship is the one that involves government participation. The Corporate entrepreneurships is the form of entrepreneurship that takes place in an existing business as a result of the introduction of new products or services with the Social entrepreneurship being the form of entrepreneurship involving the creation of self-sustaining charitable and civic organization, and profit making organizations which invest a significant part of their profit in charitable activities.

In the light of the above, it is the position of this work that entrepreneurship is the ability and deliberate decision by a person, group of people or government to initiate, control and direct the processes of production of goods and services, and bear the attendant risk thereof with the aim of making profits or provide social services. The deliverable of entrepreneurship is making or doing things differently, making or providing innovative products or services or organizing the products made or supplied.

\subsection{Concept of Development}

The concept of development has many meanings depending on the context of discourse and application. According to Sapru (2002:30), development is a continuously changing and dynamic concept that has been taking different shapes and dimensions over the years. He explains that the nature of development as seen in the early 1990s differs considerably from what was obtained in the early 1950s and even in the contemporary society.

Rodney (2005:1) also aligns with Sapru in his submission that development in any human society is a many sided process; he explains that at the level of the individual, it implies increased skills and capacity, greater freedom, creativity, selfdiscipline, responsibility and material well-being while at the level of social groups, development implies an increasing capacity to regulate both internal and external relationships.

Todaro (1982:105) is of the same opinion in his submission that development as a multi-dimensional process involves the re-organization and re-orientation of the entire economic and social system. He also explains that in addition to the improvement of input and output, development involves the radical changes in institutional, social and administrative structures as well as in popular attitudes, customs and beliefs. The main thrust of Todaro's submission is that development is both a physical process and a state of mind. The transformation of institutions is one aspect, while the other aspect is that the thinking of the people must change.

In his contribution on the concept of development, Seers (1969) argues that the best way to find out what development means is to answer such questions as: What has been happening to society, what has been happening to poverty, what has been happening to infrastructures and what has been happening to inequality? If all these mentioned are on the decline from high, then it means that development has not taken place. He argues that the mere increase in per capita income does not mean that a country is developed.

Basically, what can be deduced from the foregoing postulations on the concept of development is that it is the improvement in the state or activities of an individual, an institution or organization to the extent that what is obtainable at a particular time is better off in relation to what was previously on ground. However, it is notew orthy that the increase in the personal income of individuals or per capita income level of a nation cannot necessarily be said to represent national development. This is because there is no way that personal wealth can be equally distributed amongst the citizenry or used for the provision of social as well as infrastructural facilities like roads, safe and portable water, health care and security which are some of the main indices of national development.

\subsection{Senatorial Zone or District}

According to online Merriam Webster Dictionary, senatorial zone or district refers to a territorial division from which a senator is elected to represent it at the parliament or national assembly. Online Wikipedia views the senate as the upper house of the Nigeria's, bicameral legislature, the National Assembly of Nigeria. The National Assembly popularly known as (NASS) is the country's highest legislature whose power to make law is enshrined in chapter one, section four of the 1999 Nigerian Constitution. It consist of 109senators coming from 36 states each divided into three senatorial zones or districts each electing one senator, the Federal Capital Territory elects only one senator. 


\subsection{Other Countries Experiences as Regards Entrepreneurship Development}

According Godwin, (2017:5), "In the emerging markets, notably Brazil, Russia, India, China (BRICs) the impressive economic growth and development in the last two decades was essentially driven by a strong entrepreneurship culture". The Indian economy had a growth rate of over 7\%, at a time when most economies were shrinking; it is driven by strong entrepreneurship activity. These economies have achieved strong growth through sustainable access to technology, markets, and low-carbon industrialization, thereby putting a premium on innovative entrepreneurship.

The case that led to Arab Spring should be a lesson for a country like Nigeria regarding the need to positively engage it youths and develop their entrepreneurial skills. The story of Arab Spring is an expression of the outburst of crisis and political unrest by the abandoned youths of in the Middle East and North Africa, this has continue to create a lasting impression in the annals of our time with immense reverberations around the world. Nigeria should as a matter of importance learn from the lesson of the Arab Spring and the aftermath where the youths of the countries in that region were neglected and allowed to be mated with unprecedented levels of unemployment with the rates that was as high as $50 \%$ in some cases.

\subsection{Overview of Plateau Central Senatorial Zone of Plateau State}

Plateau Central Senatorial Zone of Plateau State is one of the three senatorial districts or zone of Plateau State. It is located in the central part of the state and comprises of five(5) local government areas. These local governments include Kanam, Kanke, Pankshin, Mangu and Bokkos. The area is bounded by Bauchi State to the North, Nasarawa to the East, Langtang LGA to the South and Shendam LGA to the West. According to the 2006 national population census, the population of the area is estimated at 1,360,300 (One million three hundred and sixty thousand three hundred people).

The occupation of the people of Plateau Central Senatorial Zone of Plateau State is predominantly farming and trading activities and this is because of the rich nature of the soil in the area and the entrepreneurial zeal that is inherent in the people. With these potentials, it is believed that the zone has the capacity to contribute immensely to the economic turnaround of Plateau State in particular and Nigeria in general. Thus, in an attempt to showcase the entrepreneurial prowess, agricultural and tourism potentials of the state and the Plateau Central Zone inclusive to the national and indeed the international business community, the Plateau Chamber of Commerce, Industries, Mines and Agriculture (PLACCIMA) on the 27 August, 2016 inaugurated an annual Trade Fair tagged "promoting entrepreneurship through MSME's for economic development".

\subsection{Entrepreneurship Development in Plateau Central Zone}

For obvious reasons, entrepreneurship development in Plateau Central Senatorial Zone of Plateau State has continued to gain momentum over the years. A number of reasons have often been adduced as to why this is so, and one of the reasons that seem most acceptable is the independent minded nature and the can-do spirit of the average indigene of the area. Apart from the employment opportunity that the tertiary institutions as Federal College of Education Pankshin in Pankshin L.G.A, College of Education Gindiri in Mangu L.G.A, Plateau State University Bokkos in Bokkos L.G.A and other government establishments provides for a limited number of the inhabitants of the area, the people have found a way around how to overcome the vicious circle of poverty that has become a common factor in most Nigerian societies.

One of the most common efforts at entrepreneurial development in the area is farming. This is usually engaged in by both men and women and it is done by cultivating cash crops in a commercial quantity, crops like Maize, Millet, Guinea Corn, Irish Potatoes and Groundnuts. They also practice livestock farming and poultry farming. The people of the Zone are well known for cultivating Tomatoes, Onions and Pepper in large quantity where trucks from different parts of the country often travel to purchase these goods on different market days within the zone.

Another effort at entrepreneurial development in the zone is trading. For those who have the financial capacity, they usually rent shops in the market or establish shopping malls to carry out their trade; while those who operate on the fringes as evident in the motor parks, military check points on the motor highways and even in some established markets in the zone, they basically hawk their goods and wares either in trucks or on their heads.

Again, there were other entrepreneurial development in the Zone by the people of the area in terms of skill acquisition which at the end of the day translates to blacksmithing, bricklaying, welding and fabrication, plumbing, electrification and carpentry, amongst others.

At the institutional level, the inauguration of an annual trade fair and recently held Jos carnival where people including those from Plateau Central Zone demonstrated their skills and brought their agricultural produce and showcase to the world with the aim of projecting individual as well as group effort at economic development is a laudable form of entrepreneurial development. Through this medium, locally produced goods and services are brought to the attention of national and even international audience with the hope of attracting their patronage.

Also at the institutional level, the Bank of Industry, and Bank of Agriculture are two amongst other Federal Government institutions that have continued to contribute to the development of entrepreneurs across the country including Plateau Central Zone and its environ, the Youth Enterprise With Innovation (YOUWIN) program introduced by the Federal Government aimed at empowering the youths to become true entrepreneurs has actually yielded significant result and also the currently ongoing N-POWER program where young unemployed graduates are been empowered have a tendency of contributing immeasurably to improving entrepreneurial development in the Zone.

Relying on the aforementioned efforts at entrepreneurship development in Plateau Central Zone of Plateau State at both individual and group levels, it is clear that these efforts have impacted positively on the people of the area over time. Some of the glaring benefits the people have enjoyed so far are: 
- Employment generation;

- Availability of agricultural products;

- Improvement in the people's standard of living;

- Access to quality education;

- Availability of standard processed food;

- Affordable standard of living.

- Increase in the income base of the area.

2.7. Challenges of Entrepreneurship Development in Plateau Central Senatorial Zone

There are several challenges that have continued to hamper the development of entrepreneurship in Nigeria, including Plateau Central Zone of Plateau State. Some of those challenges include:

\subsubsection{Infrastructural Deficiencies}

One of the major challenges facing entrepreneurship development is that of infrastructural deficiencies or decay. According to Anyadike, Emeh and Ukah (2012: 96), it is generally believed that certain basic infrastructural facilities such as good roads, good water supply, constant power, access to information and communication technology, and of most importance lack of processing and preservation facilities which causes monumental lost resulting from perishable goods like tomatoes, onions, peppers and other goods that becomes ripe and get destroyed. A case where these are lacking in a country, the growth of the economy will be adversely affected. This state of affairs has frustrated a lot of young people with bright ideas and the corresponding spirit to effect a change in some areas of our national life. Plateau Central Zone lacks most of these basic facilities.

\subsubsection{Inadequate Finance}

Another major challenge facing entrepreneurs is that of insufficient working capital. According to Onwubiko (2011), the availability of capital is central to the establishment and continued existence of any enterprise irrespective of size, focus and objective. It is the opinion of Anyadike, Emeh and Ukah (2012:97) that banks before now were reluctant to give out loans to intending entrepreneurs especially when they are young people. The processes of accessing such credits are often rigorous and dependent on the provision of collaterals as well high interest rate of as much as $21 \%$ or higher.

\subsubsection{Lack of Access to Land}

This has actually constituted a major setback to the growth of entrepreneurship especially when it is agricultural based entrepreneurial effort.

\subsubsection{Over and Multiple Taxation}

Another challenge facing entrepreneurship is the one connected with multiple taxation. Experience has shown that local government councils in the Zone often multi-tax traders, farmers and other entrepreneurs within the Zone. Such taxes usually come in the form property tax, income tax, produce tax, livestock tax, and a host of others in a bid to improve their revenue base.

\subsubsection{Theft and Other Forms of Criminal Activities}

The issue of security is a serious challenge facing entrepreneurship development. Incidents of burglary, robbery, farm looting and destruction of crops by herdsmen and other mischief-makers have continued to weigh down entrepreneurship development in Plateau Central Zone.

\subsubsection{Inadequate Entrepreneurship Education}

There is the challenge of inadequate training for would-be entrepreneurs in the country. According to Bogoro, (2015), a regrettable consequence of the immediate foregoing is the absence of adequate training that will enable people meet the challenges of the future as leaders of business and change agents. Though Entrepreneurship has been introduced in our educational curriculum in Nigeria, it focuses more on the theoretical aspect without a corresponding practical approach. This made it less effective.

\subsubsection{Weak Judicial System}

The expectation of every entrepreneur is to gain profit in form of reward from his innovations both in short or long run. Our judiciary has been deficient to enforce patent laws and copy right thereby discouraging innovations and intellectual efforts. Entrepreneurs will be more creative and innovative, when they know that there is a potential return or reward.

\section{Hypotheses}

The study will be guided by the following hypotheses derived from the research questions and objectives of the study. They include:

- HI: Entrepreneurship activities havegreatly improved the wellbeing of the people of Plateau Central Senatorial Zone.

- HI: Entrepreneurs in Plateau Central Senatorial Zone are faced with challenges that limit their success. 


\section{Theory of Enterpreneurship}

The theory of Entrepreneurial Discovery, this is one of the most widely accepted conceptions of entrepreneurship among the market process theorist. This theory has been distinguished from others based on the focus that its process is competitive in nature, market disequilibria, (balance) and the role of knowledge, expectations and learning in the operations of market, the nature and significance entrepreneurial discovery and the comparative effectiveness of alternative institutional frameworks for evoking entrepreneurship. According Knight (1921) he regards entrepreneur as a calculated risk taker. That is to say as he takes risk, his reward is the return for bearing uncertainty and is uninsurable risk. Cantillion, (1932) to him, the very function of an entrepreneur is to bear risk or to involve in an uncertain venture. Kirzner, (1997) view an entrepreneur as someone who is alert to profitable opportunities for exchange. Schumpter introduced the concept of power and innovation; he believes that entrepreneurs bring about change through the introduction of new technological processes or products. Schumpter further argues that only certain extraordinary people have the ability to become entrepreneurs and they bring about extra ordinary events.

In applying the theory to this finding, one would see the relativity in terms of the competition that the entrepreneurs often engaged in amongst themselves with the view of having an age over others. By so doing they employ sufficient use of knowledge, creativity and innovations, they also venture into calculated risk with the expectation of making gains being the reward for taking the risk.

Gap in literature: The gap identified in virtually all the literatures reviewed is that they dwelled only on entrepreneurship development in mega cities and urban centres. Emphasis was persistently giving only on the educated and literates with little or no attention been given to the rural and non-literate people who are more in number. This rural dwellers or people at the grass root are the most vulnerable as they are poor and unemployed. This research gave more impetus to such people in those areas in order to provide succor through entrepreneurship development with the understanding that when the rural communities being the areas of the research coverage are liberated from economic ills, the better it will be for Plateau State and the country as a whole.

\section{Methodology}

The data for this paper were derived solely from secondary sources: previous researches and analyses of scholars; government documents; text books, newspapers/ magazines as well as journal articles that are related to the subject as the study involved an extensive literature review which critically analyzed the present status, entrepreneurship development, issues and challenges. The research adopted a historical based type; qualitative content analysis approach was utilized for the analysis.

\section{Findings/ Discussions}

Scanning through the literature by way of analysis, it therefore presents the following outcomes:

There is a solid entrepreneurial base in Plateau Central Senatorial Zone of Plateau State, as have been observed. The literatures confirmed the fact that the people unlike before do not rely on the government solely to cater for their needs, this is because it cannot do enough. This government's inability is more of a blessing in disguise as people have become zealous, committed and dedicated to the development and sustainability of entrepreneurship realizing that it is the best available alternative.

Entrepreneurship activities have greatly improved the wellbeing of the people of Plateau Central Senatorial Zone, the entrepreneurship development in Plateau Central Senatorial Zone have not in small measure contributed a lot, as it has help in creating jobs, improving the livelihood of the people, reducing their dependence on the government and aided significantly to the rise in the revenue base of Plateau State. This entails that the first hypothesis HI is therefore accepted.

Entrepreneurs in Plateau Central Senatorial Zone are faced with challenges that limit their successes. The findings also revealed that entrepreneurs within the zone are actually confronted with myriads of challenges ranging from infrastructural deficiencies, inadequate finance, over and multiple taxation, lack of entrepreneurial education, weak judicial system among other factors have over the years and are still impeding entrepreneurship progress in the zone. With the above submission, the second hypothesis $\mathrm{HI}$ is also accepted.

\section{Conclusion}

In conclusion, it most pertinent to state in categorical terms that entrepreneurship development is very key to any well-meaning community, zone or government as highlighted in the words of Godwin, (2017:9) he asserts that entrepreneurship is a strong driver of the economic growth and can therefore, serve as a panacea for overcoming the current recession in Nigeria. This has been supported by overwhelming body of literature. Carree and Thurik, (2010) cited by Godwin, (2017) corroborating this submission, entrepreneurship generates growth and development because it serves as a vehicle for innovation and change, therefore as a conduit for knowledge spillover. To further support the claims as buttress above, Godwin, (2017:9) in Yu (1998) opined that "any policy recommendation on economic development should be based on analysis that incorporates entrepreneurship, the engine of economic growth". Therefore, entrepreneurship is "at the heart of national advantage" (Porter, 1990).

Having explored pertinent issues on entrepreneurial development in Plateau Central Zone of Plateau State, it has been discovered that much potential abound for citizens/residents of the community intending to venture into entrepreneurial activities in order to aid their living standard. However, there are certain identified challenges posing as hindrances to achieving the much desired results. Be that as it may, entrepreneurship development has impacted positively on the lives of the people of Plateau Central Zone as presented in the conceptual literature above. 


\section{Recommendations}

Based on the identified challenges facing entrepreneurial development in Plateau Central Zone of Plateau State, the following recommendations are proffered:

\subsection{Infrastructural Development}

Government at all levels are encouraged to provide necessary infrastructural facilities like opening of rural roads to link farmers to the market; establish industries, provide electricity to reduce cost of power generation to the manufacturers and industrialists, etc.

\subsection{Adequate Working Capital}

Government and other lending agencies should relax the conditions for accessing some of the financial aid packages from development banks like Bank of Industry, Bank of Agriculture, Central Bank of Nigeria, etc. This is to enable both entrepreneurs and the intending ones to have easy access to credit facilities.

\subsection{Provision of Security}

While government is encouraged to beef up security private individuals and communities members are also encouraged to ensure that criminal elements in their groups are identified and reported to appropriate authorities for necessary action.

\subsection{Training}

Even the tertiary institutions in the zone has spearheaded entrepreneurial coaching as one of the requirements for its graduating students, it is important for government to also complement this effort by establishing entrepreneurial skill acquisition centres as well as reinvigorating already existing centres across the zone.

\subsection{Tax Incentives}

Government should find a way of streamlining its tax policy especially as it pertains to entrepreneurs in the zone. As a matter of fact, it would not be out of place for the government to offer some kind of tax holidays to entrepreneurs over a period of time to ensure their stabilization before they can begin to pay taxes.

\section{References}

i. Ajekwe, C. C. M. and Ilorun, J. (2016). Concepts of entrepreneurship and intrapreneurship. In Alabar, T. T. and Tsuwa, J. T. (eds), Entrepreneurship studies and development in Nigeria - Concepts and principles

ii. Anyadike N, Emeh, I. E. J. and Ukah, F. N. (2012). Entrepreneurship development and employment generation in Nigeria: Problems and prospects, Universal Journal of Education and General Studies Vol. 1(4) pp. 088-102.

iii. Bogoro, S. E. (2015). Entrepreneurship Development. Being the convocation lecture delivered at the $2^{\text {nd }}$ Convocation Ceremony of the Kaduna State University, Kaduna on December 11, 2015.

iv. Eze, J. A. (1999), Fundamentals of Small Business Management; Enugu, Nigeria, Glanic Benture.

v. Ezenagu, I. C (2014). Entrepreneurship development in Enugu State: Issues and challenges. Being an MBA Thesis submitted to the School of Postgraduate Studies, University of Nigeria, Enugu Campus.

vi. Godwin, I.E (2017) Entrepreneurship Development, Unemployment Reduction and Economic Growth in Nigeria. Being Convocation Lecture Delivered at the 16th and 17th Combine Convocation Ceremonies of the Benue State University, Makurdi 24th March, 2017

vii. Hills, G. E. (1983), Entrepreneurship Education-A National Priority Business Education, Forum, Vol.37 No. 7.

viii. Hisrich, Rand Peters, M. (1995), Entrepreneurship: Irwin.

ix. Hornby, A.S. (1995), Oxford Advanced Learner's Dictionary, London. Oxford University Press, New York.

x. Kpelai, S. T. (2013). The impact of women entrepreneurship on economic growth in Benue State - Nigeria. IOSR Journal of Business and Management (IORS-JBM), 13(1), pp. 07-12.

xi. Plateau Chamber of Commerce, Industry, Mines and Agriculture (NCCIMA, 2016). Trade Fair/ Sales Exhibition (1st Edition brochure).

xii. Plateau Chamber of Commerce, Industry, Mines and Agriculture (NCCIMA, 2017). Trade Fair/ Sales Exhibition (2 ${ }^{\text {nd }}$ Edition brochure).

xiii. Okoloagu, J. O.J. (2015). My article of faith with Nsukka people (Campaign booklet).

xiv. Onmonya, L.O (2014) Entrepreneurship and New venture Management, Abuja: issues and Company Limited.

xv. Onuoha, C. (1994), Entrepreneurial Development in Nigeria, An Integrative Perspective, Okigwe, Avah Global Publication.

xvi. Onwubiko CM (2011). Entrepreneurship and leadership; Nigeria and the Imperative For Youth Entrepreneurial Development. Univers. J. Edu. and Gen. Stud. 1 (3), pp.55-70.

xvii. Rodney, W. (2005) How Europe Underdeveloped Africa, Abuja: Panaf Publishing Inc

xviii. Sapru, R. K, (2002), Development Administration, New Delhi: Sterling Publishers Private Limited

xix. Schumpter, J. (1961), The Theory of Economic Development. Cambridge: Harvard University Press.

xx. Seers, D. (1969). 'The Meaning of Development', International Development Review 11(4):

xxi. Shapero, A. (1975), Entrepreneurship and Economic Development, Wisconsin: Project Seed Ltd. 